\title{
QUEEN'S
UNIVERSITY
BELFAST
}

\section{Interspecific variation, habitat complexity and ovipositional responses modulate the efficacy of cyclopoid copepods in disease vector control}

Cuthbert, R. N., Dick, J. T. A., \& Callaghan, A. (2018). Interspecific variation, habitat complexity and ovipositional responses modulate the efficacy of cyclopoid copepods in disease vector control. Biological Control, 121, 80-87. https://doi.org/10.1016/j.biocontrol.2018.02.012

Published in:

Biological Control

Document Version:

Peer reviewed version

Queen's University Belfast - Research Portal:

Link to publication record in Queen's University Belfast Research Portal

\section{Publisher rights}

Copyright 2018 Elsevier.

This manuscript is distributed under a Creative Commons Attribution-NonCommercial-NoDerivs License

(https://creativecommons.org/licenses/by-nc-nd/4.0/), which permits distribution and reproduction for non-commercial purposes, provided the author and source are cited

\section{General rights}

Copyright for the publications made accessible via the Queen's University Belfast Research Portal is retained by the author(s) and / or other copyright owners and it is a condition of accessing these publications that users recognise and abide by the legal requirements associated with these rights.

Take down policy

The Research Portal is Queen's institutional repository that provides access to Queen's research output. Every effort has been made to ensure that content in the Research Portal does not infringe any person's rights, or applicable UK laws. If you discover content in the Research Portal that you believe breaches copyright or violates any law, please contact openaccess@qub.ac.uk. 
1 Interspecific variation, habitat complexity and ovipositional responses

2 modulate the efficacy of cyclopoid copepods in disease vector control

3

$4 \quad$ Ross N. Cuthbert ${ }^{\mathrm{a}, \mathrm{b}}$, Jaimie T.A. Dick ${ }^{\mathrm{a}}$ and Amanda Callaghan ${ }^{\mathrm{b}}$

5 anstitute for Global Food Security, School of Biological Sciences, Queen’s University

6 Belfast, Medical Biology Centre, 97 Lisburn Road, Belfast, BT9 7BL, Northern Ireland

$7 \quad$ benvironmental and Evolutionary Biology, School of Biological Sciences, University of

8 Reading, Harborne Building, Reading, RG6 6AS, England

9 Corresponding author: Ross N. Cuthbert (rcuthbert03@qub.ac.uk)

10

11

12

13

14

15

16

17

18

19

20 


\section{ABSTRACT}

The use of predatory biological control agents can form an effective component in the management of vectors of parasitic diseases and arboviruses. However, we require predictive methods to assess the efficacies of potential biocontrol agents under relevant environmental contexts. Here, we applied functional responses (FRs) and reproductive effort as a proxy of numerical responses (NRs) to compare the Relative Control Potential (RCP) of three cyclopoid copepods, Macrocyclops albidus, M. fuscus and Megacyclops viridis towards larvae of the mosquito Culex quinquefasciatus. The effects of habitat complexity on such predatory impacts were examined, as well as ovipositional responses of C. quinquefasciatus to copepod cues in pairwise choice tests. All three copepod species demonstrated a population destabilising Type II FR. M. albidus demonstrated the shortest handling time and highest maximum feeding rate, whilst $M$. fuscus exhibited the highest attack rate. The integration of reproductive effort estimations in the new RCP metric identifies M. albidus as a very promising biocontrol agent. Habitat complexity did not impact the FR form or maximum feeding rate of $M$. albidus, indicating that potentially population destabilising effects are robust to habitat variations; however, attack rates of $M$. albidus were reduced in the presence of such complexity. C. quinquefasciatus avoided ovipositing where M. albidus was physically present, however it did not avoid chemical cues alone. C. quinquefasciatus continued to avoid M. albidus during oviposition when both the treatment and control water were dyed; however, when an undyed, predator-free control was paired with dyed, predatortreated water, positive selectivity towards the treatment water was stimulated. We thus demonstrate the marked predatory potential of cyclopoid copepods, utilising our new RCP metric, and advocate their feasibility in biological control programmes targeting containerstyle habitats. We also show that behavioural responses of target organisms and environmental context should be considered to maximise agent efficacy. 
46 Keywords: Functional response; Numerical response; Relative Control Potential; Copepod;

47 Mosquito; Oviposition

\section{Introduction}

Mosquitoes continue to endanger public health globally through the transmission of vector-borne diseases, which account for hundreds of thousands of deaths annually (World Health Organisation, 2017). Transmission rates of arboviruses and the ecology of their vectors are shifting rapidly under environmental change (Medlock and Leach, 2015; Benelli and Mehlhorn, 2016), and at different spatiotemporal scales (Townroe and Callaghan, 2014; Cunze et al. 2016). Furthermore, incursions and proliferations of highly invasive mosquito species are occurring as a direct result of anthropogenic activity (e.g. Yee, 2016; Medlock et al. 2017), with implications for public health and persistence of native species (Juliano, 2010; Schäffner et al. 2013). Thus, the development of effective strategies to assist or augment the control of vectors of mosquito-borne disease is critical. These strategies in turn rely on rapid and reliable assessments of the efficacy of biocontrol agents under relevant environmental contexts. Culex quinquefasciatus Say, 1823 is a member of the $C$. pipiens complex, which are vectors of diseases such as West Nile virus, Sandbis virus, St Louis encephalitis, Rift Valley fever virus and lymphatic filariasis (Turell, 2012; Manimegalai and Sukanya, 2014). This mosquito breeds rapidly in artificial, urban environments, enabling a high potential for human contact (Yee, 2008). Furthermore, the species is characterised as being invasive, exhibiting the potential to negatively impact and replace native species (Juliano, 2010). Climate change may additionally bolster the potential of $C$. quinquefasciatus to invade novel ecosystems through range expansion (Samy et al. 2016). Cyclopoid copepods have had marked success in 
the biological control of Aedes aegypti mosquito larvae (e.g. Kay and Nam, 2005), and predatory impacts have been demonstrated towards Culex spp. (e.g. Calliari et al. 2003; Tranchida et al. 2009). Furthermore, the global distribution, high fecundity, environmental hardiness, voraciousness and ease of mass-production of copepods enable high levels of potential impact on target populations, whilst negating the need for potentially ecologically harmful species introductions (Marten and Reid, 2007). Yet, while interspecific variations in control efficiencies between cyclopoids have been demonstrated (Marten, 1989), as well as demographic variations across differing species strains (Marten, 1990b), many candidate copepod species are yet to be examined in the context of mosquito control.

Functional responses (FRs), which discern the per capta intake rate of a resource as a function of its availability (Holling, 1959; 1966), exhibit great utility in the quantification of interspecific differences in consumer-resource interactions (Dick et al. 2017). The search, capture and handling components of FRs can be highly informative in the contexts of biological control (O’Neil, 1990; Van Driesche and Bellows, 2011) and invasive species (Dick et al. 2014). Indeed, high impact invasive species are strongly associated with higher maximum feeding rates driven by low handling times (Dick et al. 2017), and this associates strongly with measurable changes in affected populations (i.e. ecological impact). Functional response form and magnitude can also be significant with respect to prey population stability; a Type II FR is deemed to have potentially population destabilising effects due to high levels of proportional predation at low prey densities, whilst a Type III FR may impart stability to prey by providing refugia at low prey densities (Holling, 1959). Moreover, coupling such per capita effects with corresponding numerical responses at the consumer population level can bolster the robustness of predictions of consumer impacts on resources (Dick et al. 2017). These approaches thus yield high potential in the comparison of efficacies of potential biocontrol agents. Further, context-dependencies, such as habitat complexity, can modify the 
nature of interactions within predator-prey systems and can be quantified using a FR approach (e.g. Barrios-O’Neill et al. 2015; South et al.2017). Habitat complexity may enable physical refuge for prey, directly affecting interaction strengths, and, accordingly, the structuring of ecological communities (e.g. Alexander et al. 2012). These interactions are often specific to predator-prey pairings, with habitat complexity having been found to also heighten predation (e.g. Alexander et al. 2015).

Besides direct consumptive effects, trait-mediated indirect interactions (TMIIs), including behavioural responses of target organisms to predators, can exert strong effects on predator-prey dynamics (e.g. Alexander et al. 2013), and can be as strong or stronger in their population effects (Peacor and Werner 2001; Trussell et al. 2004; 2008). Behavioural responses of mosquitoes to predator cues can be marked, yet also species-specific (e.g. Vonesh and Blaustein, 2010; Zuhurah and Lester, 2011). Thus, considering oviposition selectivity among potential habitats by mosquitoes is of integral importance to biological control, particularly for species which invest all of their eggs in one environment at one time, such as C. quinquefasciatus (Wachira et al. 2010). Broadly, natural selection favours individuals that are able to actively evade predation through avoidance of oviposition habitats containing predators (Sih, 1986; Blaustein and Chase, 2007). Water colouration, serving as a proxy for nutritional load, has also been demonstrated to significantly attract oviposition by Culex mosquitoes (Ortiz Perea and Callaghan, 2017). The effects of the presence of copepods on oviposition of mosquitoes has been seldom considered, however, Torres-Estrada et al. (2001) found that $A$. aegypti preferentially oviposited in water treated with the copepod Mesocyclops longisetus due to the emission of attractive compounds. This finding is an oddity in the context of the general avoidance by mosquitoes of other predators (Vonesh and Blaustein, 2010). 
Here, we quantify the FRs of three locally-abundant and widespread cyclopoid copepods, Macrocyclops albidus (Jurine 1820), Macrocyclops fuscus (Jurine, 1820) and Megacyclops viridis (Jurine, 1820) towards larvae of the mosquito C. quinquefasciatus. We then combine maximum feeding rate and attack rate estimations generated from the FRs with reproductive effort data from Maier (1994) to compare the Relative Control Potential (RCP; Cuthbert et al. 2018) among the three species. Benthic habitat complexity is integrated in a separate experiment to assess potential context-dependencies relevant to the efficacy of copepods in their predation of $C$. quinquefasciatus. Furthermore, we utilise pairwise choice tests to assess the ovipositional responses of $C$. quinquefasciatus to the predators in several bioassays consisting of visual and chemical cues from predatory copepods, and examine whether the integration of pond dye reduces avoidance behaviour by the mosquito, hence enhancing biocontrol efforts. Thus, we seek to decipher the most effective biocontrol agent using the RCP metric, and consider the effects of habitat complexity and target prey behavioural responses on agent efficacies.

\section{Methods}

\subsection{Experimental organisms}

The predators, Macrocylops albidus, M. fuscus and Megacyclops viridis, were collected from Glastry Clay Pit Ponds, Northern Ireland (54²9'18.5"N; 5²8'19.9"W) during January 2017 using a polypropylene dipper, transported to Queen’s Marine Laboratory, Portaferry in source water, and maintained at $25 \pm 2{ }^{\circ} \mathrm{C}$ under a 16:8 light:dark regime. Cultures were initiated separately for each species by placing a single ovigerous adult female into $250 \mathrm{~mL}$ dechlorinated tap water, with the protists Paramecium caudatum and 
$10 \mathrm{~L}$ tanks and fed on the same protist diet, while autoclaved wheat seeds were used to sustain the protists.

The prey, Culex quinquefasciatus, were obtained from a laboratory colony maintained at the same conditions as the predators. Culex quinquefasciatus were originally collected in Cyprus in 2005 by Dr A. Callaghan and had been reared in laboratory conditions at the University of Reading since then. Adults were maintained in $32.5 \mathrm{~cm}^{3}$ cages (Bugdorm, Watkins and Doncaster, Leominster, England). Defibrinated horse blood (TCS Biosciences, Buckingham, England) was fed to adults three times per week using an artificial membrane feeding system (Hemotek Ltd., Accrington, England). Cotton pads soaked in 10\% sucrose solution were provided for other sustenance. A black oviposition cup containing $200 \mathrm{~mL}$ tap water was kept in each cage, with egg rafts removed three times per week and placed into $3 \mathrm{~L}$ larval bowls containing tap water and ground guinea pig pellets (Pets at Home, Newtownabbey, Northern Ireland) provided ad libitum until mosquito pupation.

\subsection{Experiment 1: Functional responses (FRs) and Relative Control Potential (RCP)}

Adult, non-ovigerous female M. albidus (1.6 - 1.8 mm body length), M. fuscus (1.9$2.1 \mathrm{~mm}$ body length) and $M$. viridis (2.0 $-2.3 \mathrm{~mm}$ body length) were selected for experiments to standardise predators as cyclopoids are sexually dimorphic (Laybourn-Parry et al. 1988). Predators were starved for 24 hours to standardise hunger levels. Prey, first instar C. quinquefasciatus (1.1- $1.3 \mathrm{~mm})$, were provided to copepods at six densities $(2,4,8,15,30$, $60, n=3$ per density) in $20 \mathrm{~mL}$ arenas of $42 \mathrm{~mm}$ diameter, and allowed to settle for three hours prior to the addition of individual predators. Predators were allowed to feed for 24 hours, after which they were removed and remaining live prey counted. Controls consisted of three replicates at each prey density without a predator. We integrated reproductive effort 
data derived from Maier (1994) with maximum feeding rates and attack rates to calculate RCP among the three predators (see below).

\subsection{Experiment 2: Habitat complexity}

Adult female $M$. albidus (1.6 - $1.8 \mathrm{~mm}$ body length) were selected for experiments and starved for 24 hours to standardise hunger levels. Prey, first instar C. quinquefasciatus (1.1- $1.3 \mathrm{~mm})$, were provided at the same densities ( $n=3$ per experimental group) and in the same arenas as Experiment 1, and also allowed the same acclimation. However, arenas exhibited either 'low' or 'high' complexity, with 'low' complexity treatment arenas being vacant and 'high' complexity arenas containing five polypropylene caps ( $7 \mathrm{~mm}$ diameter, 10 $\mathrm{mm}$ height), arranged in a uniform array (Figure 1) and positioned using non-toxic mounting putty. As in Experiment 1, predators were allowed to feed for 24 hours before being removed and remaining live prey counted. Controls consisted of three replicates at each prey density and complexity level without predators.

\subsection{Experiment 3: Ovipositional responses}

We assessed ovipositional preferences of $C$. quinquefasciatus with pairwise choice tests. Recently emerged female C. quinquefasciatus were blood fed for the first time over a 24 hour period. Following this, each experimental replicate consisted of cages $\left(32.5 \mathrm{~cm}^{3}\right)$ containing 20 blood-fed females and a 10\% sucrose solution, refilled ad libitum. Mosquitoes were maintained in these cages for 144 hours in bioassay 1, and 168 hours in following bioassays, at $25{ }^{\circ} \mathrm{C} \pm 2{ }^{\circ} \mathrm{C}$ and in a 16:8 light:dark regime. In all bioassays, control and treatment cups were established 48 hours before being added to cages in $80 \mathrm{ml}$ arenas of 6.5 $\mathrm{cm}$ diameter using water from a continuously aerated source. Adult female $M$. albidus were used to produce all bioassays and were fed with mosquito larvae ad libitum prior to use. In bioassay 1 , three copepods were physically present in the treatment cups when added to the 
cages ( $n=7$ per experimental group). In bioassay 2, three copepods were removed from the treatment cups immediately before being added to cages ( $n=13$ per experimental group). In

bioassay three, ten copepods were ground up using a pestle and mortar and added to treatment cups ( $n=7$ per experimental group). In bioassays 4 and 5, three copepods were added to arenas containing black liquid pond dye $\left(0.3 \mathrm{~g} \mathrm{~L}^{-1}\right.$, Dyofix, Leeds, United Kingdom, $n=7$ per experimental group). Controls lacked predators, and those in bioassays 1-3 and 5 consisted of dechlorinated tap water, whilst controls in bioassay 4 consisted of dyed dechlorinated tap water. Paired cups were added to opposing corners within cages in a randomised design and mosquitoes given 48 hours to oviposit. Following this, cups were removed and the numbers of egg rafts counted.

\subsection{Statistical analyses}

Statistical analyses were undertaken in R v3.4.2. (R Core Team, 2017). In

Experiments 1 and 2, logistic regression was used to infer FR types with respect to proportions of prey eaten as functions of prey density. Categorically, a Type II FR is indicated by a significantly negative first order term. Rogers' random predator equation was fitted to the data as prey were not replaced as they were consumed (Juliano, 2001):

$$
N_{e}=N_{0}\left(1-\exp \left(a\left(N_{e} h-T\right)\right)\right)
$$

where $N_{e}$ is the number of prey eaten, $N_{0}$ is the initial density of prey, $a$ is the attack constant, $h$ is the handling time and $T$ is the total experimental period. The Lambert $\mathrm{W}$ function was used to aid model fitting (Bolker, 2008). Estimates of attack rate, handling time and maximum feeding rate $(1 / h)$ were non-parametrically bootstrapped $(n=30)$ to provide means and standard errors (SEs). In Experiment 1, we calculated RCP (see Cuthbert et al. 2018) using maximum feeding and attack rates with reproductive effort data (clutch weight 
produced per female body weight per day) from Maier (1994) as a proxy for the numerical response:

$$
R C P=\left(\frac{\text { FR agent } A}{\text { FR agent } B}\right) \times\left(\frac{\text { RE agent } A}{\text { RE agent } B}\right)
$$

where FR represents maximum feeding or attack rates, and RE is reproductive effort. Where $\mathrm{RCP}=1$, no difference between biocontrol agents is predicted; where $\mathrm{RCP}>1$, agent $\mathrm{A}$ has a greater control potential than agent $\mathrm{B}$, whilst where $\mathrm{RCP}<1$, agent $\mathrm{A}$ has a lesser control potential than agent B (see Dick et al. 2017; Cuthbert et al. 2018). Uncertainty around RCP values, in the form of confidence intervals (CIs) and $p$-values, were calculated as per Dick et al. (2017). RCP 'biplots' were used to visually illustrate the results (e.g. see Cuthbert et al. 2018).

In Experiment 3, we used Shapiro-Wilk and Bartlett tests to assess normality and homoscedasticity for each treatment pair, respectively. Where data were normal and homoscedastic, we employed paired $t$-tests for analysis of oviposition data. Wilcoxon tests were used where data did not meet the assumptions of a parametric test. We calculated oviposition activity index (OAI) values (Kramer and Mulla, 1979), which enable data to be standardised as proportions for graphical visualisation:

$$
\mathrm{OAI}=\frac{(\mathrm{NT}-\mathrm{NC})}{(\mathrm{NT}+\mathrm{NC})}
$$


demonstrated for the treatment rather than control cups, whilst negative values show preference for controls.

\section{Results}

\subsection{Experiment 1: Functional responses (FRs) and Relative Control Potential (RCP)}

Prey survival in controls exceeded $99 \%$ and thus most prey deaths were attributed to cyclopoid copepod predation. Type II FRs were found for each predator (Table 1; Figure 2). M. albidus demonstrated the shortest handling times and, inversely, highest maximum feeding rates, followed by $M$. viridis, which exhibited shorter handling times and higher maximum feeding rates than M. fuscus (Table 2; Figure 3a, b). Attack rates varied among the predators; M. fuscus exhibited greater attack rates than M. albidus, which in turn exhibited greater attack rates than $M$. viridis (Table 2; Figure 3c).

Relative Control Potential (RCP) calculations and probabilities are illustrated in Table 2. When maximum feeding rates are used in the RCP metric (Figure 4a), M. albidus exhibits greater efficacy in controlling C. quinquefasciatus than both $M$. fuscus $(\mathrm{RCP}=2.73)$ and $M$. viridis $(\mathrm{RCP}=1.33)$. $M$. viridis exhibits a greater efficacy compared to $M$. fuscus $(\mathrm{RCP}=$ 2.13). With attack rates incorporated into the RCP metric (Figure 4b), M. albidus demonstrates similar efficacy predictions to M. fuscus $(\mathrm{RCP}=0.96)$, and greater efficacy than M. viridis $(\mathrm{RCP}=1.42) . M$. viridis exhibits a lower efficacy than $M$. fuscus here $(\mathrm{RCP}=$ 0.71). These calculations are bolstered graphically in Figure 4 using RCP biplots, with $M$. albidus showing greatest efficacy overall when maximum feeding rates are integrated, and similarities in efficacies projected between these predators when attack rates are applied.

\subsection{Experiment 2: Habitat complexity}

Prey survival in controls was $100 \%$, and thus all prey deaths in treatment groups were attributed to predation by cyclopoid copepods. Type II FRs were observed under both levels 
of habitat complexity (Table 3; Figure 5). Handling times and maximum feeding rates were similar between both levels of habitat complexity (Figure 6a, b). Attack rates were higher in low compared to high complexity treatments (Figure 6c).

\subsection{Experiment 3: Ovipositional responses}

In bioassay 1, significantly fewer egg rafts were laid in cups containing copepods in comparison to controls ( $W=45, p=0.01$ ). However, in bioassays 2 and 3 , no significant differences in oviposition levels were detected between the chemical treatments with predatory cyclopoids removed $(t=1.41, d f=12, p=0.18$ ), or with ground cyclopoids $(W=$ 29.5, $p=0.55)$. In bioassay 4, significantly fewer egg rafts were oviposited in dyed water containing predatory copepods compared to dyed water alone $(t=5.35, d f=6, p=0.002)$. In bioassay 5, significantly more egg rafts were laid in cups treated with both dye and copepods compared to undyed, predator-free controls $(t=5.60, d f=6, p=0.001)$. Figure 7 illustrates OAI scores for each of the five treatments graphically.

\section{Discussion}

The development and application of control strategies to combat mosquito-borne disease is of immense public health importance (Benelli and Mehlhorn, 2016), particularly in light of changes to population dynamics being driven by globalisation, urbanisation and climate change (Townroe and Callaghan, 2014; Medlock and Leach, 2015), as well as emergent context-dependencies (e.g. Fischer et al. 2013). Biological control of mosquitoes using predatory agents can be an effective tool to assist or augment control strategies targeting important disease vector species (e.g. Nam et al. 2012). In this context, the coupled use of functional and numerical responses (or their proxies) provides a robust comparative framework to decipher and project the potential efficacy in controlling target organisms by agents (see Dick et al. 2017; Cuthbert et al. 2018). Consumer-resource interactions are, 
however, subject to a range of context-dependencies which may modulate interaction strengths, such as habitat complexity (Barrios-O’Neill et al. 2015; Alexander et al. 2015), temperature (Wasserman et al. 2016; Cuthbert et al. 2018) and parasitism (Laverty et al. 2017a). Such effects may reduce or nullify the potential of agents in the field, and thus are critical to consider during biocontrol agent evaluations. Furthermore, elucidating behavioural responses, such as those relating to ovipositional choice, of target organisms is imperative to derive a holistic view of agent efficacy, particularly in ecological systems where organisms are not confined to a single habitat patch, such as is often the case with container-breeding mosquitoes in urban and peri-urban environments (Silberbush and Blaustein, 2011; Townroe and Callaghan, 2014).

Here, we applied functional responses (FRs) to assess the potential predatory impact of three native cyclopoid copepods towards $C$. quinquefasciatus, a container-breeding mosquito and capable vector of diseases such as West Nile virus and lymphatic filariasis (Turell, 2012; Manimegalai and Sukanya, 2014). Further, we examined the impact of habitat complexity on interaction strengths in this predator-prey system and discerned the ovipositional responses of $C$. quinquefasciatus to predatory cues. The focal predators, $M$. albidus, M. fuscus and M. viridis all exhibited potentially population destabilising Type II FRs towards first instar C. quiquefasciatus. This characteristic encompasses high levels of killing at low prey densities, limiting conditions for prey refugia (Holling, 1959) and, concurrently, avoids the compensatory effect of reduced competitive interactions in surviving mosquito prey (Juliano, 2007). This destabilising FR may thus reduce the likelihood of size refuge attainment in prey, given that cyclopoid copepods only effectively consume early instar mosquito larvae (Marten and Reid, 2007). Macrocyclops albidus exhibited the highest magnitude FR of the predators, characterised by comparatively low handling times and thus high maximum feeding rates. M. fuscus demonstrated the greatest attack rates, indicating 
strong per capita efficacies at lower prey densities. M. albidus has already shown promise during previous trials for the control of arbovirus vectors (e.g. Marten, 1990a; Veronesi et al. 2015), however the predatory potential of the congeneric $M$. fuscus had yet to be examined prior to this study. The use of RCP illustrates that M. albidus exhibits the highest efficacy for the control of $C$. quinquefasciatus when maximum feeding rates are integrated, particularly given the comparatively low reproductive effort of M. fuscus (Maier, 1994). When attack rates are used in the RCP metric, similarities between $M$. albidus and $M$. fuscus are deduced. However, in a meta-analysis of the impacts of invasive species, the maximum feeding rate combined with numerical response proxies gave $100 \%$ association with degree of ecological impact. That is, the 'offtake rate' of prey, sometimes known as the 'total response', was the best predictor of consumer impact on resources (Dick et al. 2017; Laverty et al. 2017b). Also, the attack rate in experiments where prey are not replaced following consumption may be artificially constrained (Alexander et al. 2012). Thus, we propose that, while attack rates may give insight into predation at low prey densities, it is the maximum feeding rate combined with numerical response proxies that gives best RCP predictions.

Habitat complexity was found to modulate interactions between M. albidus and $C$. quinquefasciatus through a reduction in attack rates where complexity was present. However, the Type II FR exhibited was robust to variations in habitat complexity, and thus population destabilising effects towards disease vectors such as $C$. quinquefasciatus may be sustained under such conditions. Indeed, habitat structure has previously been demonstrated to affect survivability of mosquito prey to predatory copepods (e.g. Rey et al. 2004), however, densitydependent effects (i.e. FRs) had yet to be considered. Our results contrast to other studies whereby variations to benthic habitat structure fundamentally change the nature or magnitude of the observed FR (e.g. Alexander et al. 2012; but see Alexander et al. 2015). Furthermore, handling times and thus maximum feeding rates were largely unaffected by habitat 
complexity, and hence feeding magnitudes of $M$. albidus are maintained under these contexts. These traits favour the application of $M$. albidus as a biocontrol agent given the dynamic nature of container-style habitats within which C. quinquefasciatus colonises (Bohart and Washino, 1978; Meyer and Durso, 1993).

Predator avoidance by culicids during oviposition is common (see Vonesh and Blaustein, 2010), yet interspecific variations with respect to coexistence patterns are commonplace (e.g. van Dam and Walton, 2008). Furthermore, interacting environmental factors and density-dependent effects may further modulate oviposition responses (Silberbush and Blaustein, 2011; Silberbush et al. 2014). Pairwise choice tests have been deemed more powerful and advocated over multiple-choice comparisons when examining responses to predatory cues (Silberbush and Blaustein, 2011). Avoidance behaviours have been deemed stronger for mosquito species which oviposit directly onto waterbodies, such as Culex spp. (Vonesh and Blaustein, 2010). Our results are indicative of predator avoidance behaviour of C. quinquefasciatus towards $M$. albidus when the copepod is physically present. Yet, these effects were dependent upon the nature of the aquatic environment. Generally, this contrasts with limited results which demonstrate positive selection by A. aegypti for sites treated with cyclopoid copepods (Torres-Estrada et al. 2001). We found no evidence for avoidance behaviour in the presence of chemical cues of M. albidus. Mosquitoes within the C. pipiens complex have been shown to prefer black dyed water when ovipositing, likely as a result of greater perceived depth or a higher nutritional load for their progeny (Ortiz Perea and Callaghan, 2017). Here, when both predator and control treatments were dyed, $C$. quinquefasciatus continued to avoid M. albidus in pairwise tests. However, when the control treatment was undyed and predator-free, C. quinquefasciatus demonstrated clear preference for dyed, predator-treated water. These results indicate interactive complexity, whereby the preference towards dyed habitats overrides the avoidance stimulus relating to physical 
predator presence. Thus, the use of dye in synergy with predator inoculations may foster more effective biocontrol potential in certain environments.

In conclusion, the use of FR demonstrates strong predatory impact and potential for the application of cyclopoid copepods in biocontrol strategies, particularly in light of Type II forms conducive to population destabilising effects. We illustrate that this overarching FR form is robust to interspecific variations and habitat complexities, however, variations in underlying FR parameters are apparent among cyclopoid species and habitat complexities. The integration of reproductive effort estimations allows the better resolution of differential RCP between the species, favouring the use of M. albidus over other comparators overall. These results corroborate generally with the success of cyclopoid copepods in mosquito control during field trials, whereby large-scale eradication has been achieved (Kay and Nam, 2005; Nam et al. 2012), and the particular interest in the use of M. albidus in field-based trials which has been demonstrated (e.g. Marten, 1990a; Veronesi et al. 2015). Understanding the non-consumptive effects of predators is central to biocontrol applications and broader concerns relating to predator-prey interactions (Preisser and Bolnick, 2008; Vonesh and Blaustein, 2010). Here, we demonstrate context-dependent avoidance behaviour of $C$. quinquefasciatus in response to copepod predators, yet highlight that the synergistic use of dye may bolster the efficacy of biocontrol releases due to favoured oviposition in these conditions. Additional field-based research to elucidate the effects of dye on community structure and predatory impact is thus warranted.

\section{Acknowledgements}

This study was funded through a PhD studentship provided by the Department for the Economy, Northern Ireland. We thank Maria Holyńska, Museum and Institute of Zoology, 
382

383

384

385

386

387

388

389

390

391

392

393

394

395

396

397

398

399

400

401

402

403

404

405

406

Warsaw, Poland, for assistance with copepod identification. We also are grateful to two anonymous referees for helpful comments.

\section{References}

Alexander, M.E., Dick, J.T.A., O’Connor, N.E., Haddaway, N.R., Farnsworth, K.D., 2012. Functional responses of the intertidal amphipod Echinogammarus marinus: effects of prey supply, model selection and habitat complexity. Mar. Ecol. Prog. Ser. 468, 191-202. http://dx.doi.org/10.3354/meps09978.

Alexander, M.E., Dick, J.T.A., O’Connor, N.E., 2013. Trait-mediated indirect interactions in a marine intertidal system as quantified by functional responses. Oikos 122(11), 1521-1531. http://dx.doi.org/10.1111/j.1600-0706.2013.00472.x.

Alexander, M.E., Kaiser, H., Weyl, O.L.F., Dick, J.T.A., 2015. Habitat simplification increases the impact of a freshwater invasive fish. Environ. Biol. Fish. 98(2), 477-486.

http://dx.doi.org/10.1007/s10641-014-0278-Z.

Benelli, G., Mehlhorn, H., 2016. Declining malaria, rising of dengue and Zika virus: insights for mosquito vector control. Parasitol. Res. 115(5), 1747-1754.

http://dx.doi.org/10.1007/s00436-016-4971-z.

Barrios-O’Neill, D., Dick, J.T.A., Emmerson, M.C., Ricciardi, A., MacIsaac, H.J., 2015. Predator-free space, functional responses and biological invasions. Funct. Ecol. 29(3), 377-384. http://dx.doi.org/10.1111/1365-2435.12347. 
California Press, Berkeley.

409

Bolker, B.M., 2008. Ecological Models and Data in R. Princeton University Press,

Princeton.

412

Blaustein, L., Chase, J.M., 2007. Interactions between mosquito larvae and species

that share the same trophic level. Annu. Rev. Entomol. 52, 489-507.

https://doi.org/10.1146/annurev.ento.52.110405.091431.

416

Calliari, D., Sanz, K., Martínez, M., Cervetto, G., Gómez, M., Basso, C., 2003.

Comparison of the predation rate of freshwater cyclopoid copepod species on larvae of the mosquito Culex pipiens. Med. Vet. Entomol. 17, 339-342.

420

Cunze, S., Koch, L.K., Kochmann, J., Klimpel, S., 2016. Aedes albopictus and Aedes

japonicus - two invasive mosquito species with different temperature niches in Europe.

Parasit. Vectors 9(1), 573. http://dx.doi.org/10.1186/s13071-016-1853-2.

Cuthbert, R.N., Dick, J.T.A., Callaghan, A., Dickey, J.W.E., 2018. Biological control

agent selection under environmental change using functional responses, abundances and

fecundities; the Relative Control Potential (RCP) metric. Biol. Control 121, 50-57.

https://doi.org/10.1016/j.biocontrol.2018.02.008.

Dick, J.T.A., Alexander, M.E., Jeschke, J.M., Ricciardi, A., MacIsaac, H.J.,

Robinson, T.B., Kumschick, S., Weyl, O.L.F., Dunn, A.M., Hatcher, M.J., Paterson, R.A., 
432 Farnsworth, K.D., Richardson, D.M., 2014. Advancing impact prediction and hypothesis

433 testing in invasion ecology using a comparative functional response approach. Biol. Invasions 16(4), 735-753. http://dx.doi.org/10.1007/s10530-013-0550-8.

435

Dick, J.T.A., Laverty, C., Lennon, J.J., Barrios-O'Neill., D., Mensink, P.J., Britton,

R., Médoc, V., Boets, P., Alexander, M.E., Taylor, N.G., Dunn, A.M., Hatcher, M.J.,

Rosewarne, P.J., Crookes, S., MacIsaac, H.J., Xu, M., Ricciardi, A., Wasserman, R.J.,

Ellender, B.R., Weyl, O.L.F., Lucy, F.E., Banks, P.B., Dodd, J.A., MacNeil, C., Penk, M.R.,

Aldridge, D.C., Caffrey, J.M., 2017. Invader Relative Impact Potential: a new metric to

understand and predict the ecological impacts of existing, emerging and future invasive alien species. J. Appl. Ecol. 54(4), 1259-1267. http://dx.doi.org/10.1111/1365-2664.12849.

complexity on the predation of Buenoa fuscipennis (Heteroptera: Notonectidae) on mosquito immature stages and alternative prey. J. Vector Ecol. 38(2), 215-223.

https://doi.org/10.1111/j.1948-7134.2013.12033.x.

Holling, C.S., 1959. Some characteristics of simple types of predation and parasitism.

Can. Entomol. 91(7), 385-398. http://dx.doi.org/10.4039/Ent91385-7. density. Mem. Entomol. Soc. Can. 48: 1-86. https://doi.org/10.4039/entm9848fv. 
457 Experiments. Oxford University Press, Oxford, pp. 178-196.

$458 \quad$ http://dx.doi.org/10.4319/lo.1995.40.8.1533.

459

460

Juliano, S.A., 2007. Population dynamics, in: T.G. Floore (Ed.). Biorational Control

461

of Mosquitoes. J. Am. Mosq. Contr. Assoc. 23 (Suppl. 2), pp. 93-109.

462

463

Juliano, S.A., 2010. Coexistence, exclusion, or neutrality? A meta-analysis of

464

competition between Aedes albopictus and resident mosquitoes. Israel J. Ecol. Evol. 56(3-4),

465

325-351. https://doi.org/10.1560/ijee.55.3-4.325.

466

467

Kay, B.H., Nam, V.S., 2005. New strategy against Aedes aegypti in Vietnam. Lancet

468

365(9459), 613-617. http://dx.doi.org/10.1016/S0140-6736(05)17913-6.

469

470

Kramer, W.L., Mulla, M.I.R.S., 1979. Oviposition attractants and repellents of

471

mosquitoes: oviposition responses of Culex mosquitoes to organic infusions. Environ.

472 Entomol. 8(6), 1111-1117. https://doi.org/10.1093/ee/8.6.1111.

473

474

Laverty, C., Brenner, D., McIlwaine, C., Lennon, J.J., Dick, J.T.A., Lucy, F.E.,

475 Christian, K.A., 2017a. Temperature rise and parasitic infection interact to increase the

476 impact of an invasive species. Int. J. Parasitol. 47(5), 291-296.

477 http://dx.doi.org/10.1016/j.ijpara.2016.12.004.

478

479

Laverty, C., Green, K.D., Dick, J.T.A., Barrios-O'Neill, D., Mensink, P.J., Médoc, V.,

480 Spataro, T., Caffrey, J.M., Lucy, F.E., Boets, P., Britton, J.R., Pegg, J., Callagher, C., 
481

482

483

484

485

486

487

488

489

490

491

492

493

494

495

496

497

498

499

500

501

502

503

504

505

2017b. Assessing the ecological impacts of invasive species based on their functional

responses and abundances. Biol. Invasions 19(5), 1653-1665.

http://dx.doi.org/10.1007/s10530-017-1378-4.

Laybourn-Parry, J., Abdullahi, B.A., Tinson, S.V., 1988. Temperature-dependent energy partitioning in the benthic copepods Acanthocyclops viridis and Macrocyclops albidus. Can.

J. Zool. 66(12), 2709-2713. https://doi.org/10.1139/z88-397.

Maier, G., 1994. Patterns of life history among cyclopoid copepods of central Europe. Freshw. Biol. 31(1), 77-86. https://doi.org/10.1111/j.1365-2427.1994.tb00840.x.

Manimegalai, K., Sukanya, S., 2014. Biology of the filarial vector, Culex

quinquefasciatus (Diptera:Culicidae). Int. J. Curr. Microbiol. Appl. Sci. 3(4), 718-24.

Marten, G.G., 1989. A survey of cyclopoid copepods for control of Aedes albopictus larvae. Bull. Soc. Vector Ecol. 14(2), 232-236.

Marten, G.G., 1990a. Elimination of Aedes albopictus from tire piles by introducing Macrocyclops albidus (Copepoda, Cyclopidae). J. Am. Mosq. Control Assoc. 6(4), 689-693.

Marten G.G., 1990b. Issues in the development of cyclops for mosquito control.

Arbovirus Res. Aust. 5, 159-164.

Marten, G.G., Reid, J.W., 2007. Cyclopoid copepods. J. Am. Mosq. Control Assoc. 23(2), 65-92. http://dx.doi.org/10.2987/8756-971X(2007)23\%5B65:CC\%5D2.0.CO;2. 
risk in the UK. Lancet Infect. Dis. 15(6), 721-730. http://dx.doi.org/10.1016/S1473-

3099(15)70091-5.

510

511

Medlock, J.M., Vaux, A.G.C., Cull, B., Schäffner, F., Gillingham, E., Pfluger, V.,

512

Leach, S.A., 2017. Detection of the invasive mosquito species Aedes albopictus in southern

England. Lancet Infect. Dis. 17(2), 140. http://dx.doi.org/10.1016/S1473-3099(17)30024-5.

514

Meyer, R.P., Durso, S.L. 1993. Identification of the mosquitoes of California. Mosq.

Vector Contr. Assoc. Cali., Sacramento, USA.

517

518

Nam, V.S., Yen, N.T., Duc, H.M., Tu, T.C., Thang, V.T., Le, N.H., Le Loan, L.,

Huong, V.T.Q., Khanh, L.H.K., Trang, H.T.T., Lam, L.Z.Y., Kutcher, S.C., Aaskov, J.G.,

Jeffery, J.A.L., Ryan, P.A., Kay, B.H., 2012. Community-based control of Aedes aegypti by

521

using Mesocyclops in Southern Vietnam. Am. J. Trop. Med. Hyg. 86(5), 850-859.

522

http://dx.doi.org/10.4269/ajtmh.2012.11-0466.

523

524

525

biological control of insect pests in agricultural systems, in: Dunn, P.E., Baker, R.R. (Eds.)

526

New directions in biological control: alternatives for suppressing agricultural pests and

527 diseases. Alan R. Liss, Inc., New York, pp. 83-96.

528

Ortiz Perea, N., Callaghan, A., 2017. Pond dyes are Culex mosquito oviposition attractants. PeerJ 5, e3361. http://dx.doi.org/ 10.7717/peerj.3361. 
533 the net effects of a predator. Proc. Natl. Acad. Sci. USA 98, 3904-3908.

534 https://doi.org/10.1073/pnas.071061998.

535

536

537

538

539

540

541

542

543

544

545

546

547

548

549

550

551

552

Preisser, E.L., Bolnick, D.I., 2008. The many faces of fear: comparing the pathways and impacts of nonconsumptive predator effects on prey populations. PLoS ONE 3(6), e2465. https://doi.org/10.1371/journal.pone.0002465.

R Core Team, 2017. R: A language and environment for statistical computing. R

Foundation for Statistical Computing, Vienna.

2

Rey, J.R., O’Connell, S., Suárez, S., Menéndez, Z., Lounibos, L.P., Byer, G. 2004.

Laboratory and field studies of Macrocyclops albidus (Crustacea: Copepoda) for biological

control of mosquitoes in artificial containers in a subtropical environment. J. Vector Ecol. 29

(1), 124-134. 7

Samy, A.M., Elaagip, A.H., Kenawy, M.A., Ayres, C.F.J., Townsend Peterson, A., Soliman, D.A., 2016. Climate change influences on the global potential distribution of the mosquito Culex quinquefasciatus, vector of West Nile virus and lymphatic filariasis. PLOS One 11(10), e0163863. https://doi.org/10.1371/journal.pone.0163863. 
https://doi.org/10.1111/1469-0691.12189.

556

557

Sih, A., 1986. Antipredator responses and the perception of danger by mosquito

larvae. Ecol. 67(2), 434. https://doi.org/10.2307/1938587.

559

560

Silberbush, A., Blaustein, L., 2011. Mosquito females quantify risk of predation to

561 their progeny when selecting an oviposition site. Funct. Ecol. 25(5), 1091-1095.

562

https://doi.org/10.1111/j.1365-2435.2011.01873.x.

563

564

Silberbush, A., Tsurim, I., Margalith, Y., Blaustein, L., 2014. Interactive effects of

565

salinity and a predator on mosquito oviposition and larval performance. Popul. Ecol. 175(2),

566

565-575. https://doi.org/10.1007/s00442-014-2930-x.

567

568

South, J., Dick, J.T.A., McCard, M., Barrios-O'Neill, D., Anton, A., 2017. Predicting

569

predatory impact of juvenile invasive lionfish (Pterois volitans) on a crustacean prey using

570 functional response analysis: effects of temperature, habitat complexity and light regimes.

571 Environ. Biol. Fish. 100(10), 1155-1165. http://dx.doi.org/10.1007/s10641-017-0633-y.

572

573

Townroe, S., Callaghan, A., 2014. British container breeding mosquitoes: The impact

574 of urbanisation and climate change on community composition and phenology. PLoS ONE,

575 9(4), e95325. https://doi.org/10.1371/journal.pone.0095325. 
Torres-Estrada, J., Rodriguez, M.H., Cruz-Lopez, L., Arredondo- Jimenez, J.I., 2001.

Selective oviposition by Aedes aegypti (Diptera: Culicidae) in response to Mesocyclops longisetus (Copepoda: Cyclopoida) under laboratory and field conditions. J. Med. Entomol. 38(2), 188-192. https://doi.org/10.1603/0022-2585-38.2.188.

Tranchida, M.C., Micieli, M.V., Maciá, A., García, J.J., 2009. Native Argentinean cyclopoids (Crustacea: Copepoda) as predators of Aedes aegypti and Culex pipiens (Diptera: Culicidae) mosquitoes. Rev. Biol. Trop. 57(4), 1059-1068.

\footnotetext{
Trussell, G.C., Ewanchuk, P.J., Bertness, M.D., Silliman, B.R., 2004. Trophic cascades in rocky shore tide pools: distinguishing lethal and nonlethal effects. Oecologia 139(3), 427-432. https://doi.org/10.1007/s00442-004-1512-8.

Trussell, G.C., Ewanchuk, P.J., Matassa, C.M., 2008. Resource identity modifies the influence of predation risk on ecosystem function. Ecol. 89(10), 2798-2807.

https://doi.org/10.1890/08-0250.1.

Turell, M.J., 2012. Members of the Culex pipiens complex as vectors of viruses. J. Am. Mosq. Control Assoc. 28(4), 123-6. https://doi.org/10.2987/8756-971x-28.4.123.

Van Dam, A.R., Walton, W.E., 2008. The effect of predatory fish exudates on the ovipostional behaviour of three mosquito species: Culex quinquefasciatus, Aedes aegypti and Culex tarsalis. Med. Vet. Entomol. 22(4), 399-404. https://doi.org/10.1111/j.1365-

\subsubsection{4.x.}


602

603

604

605

606

607

608

609

610

611

612

613

614

615

616

617

618

619

620

621

622

623

624

625

626

Van Driesche, R., Bellows, T.S., 2011. Biological Control. Springer, Berlin.

https://doi.org/10.1007/978-1-4613-1157-7.

Veronesi, R., Carrieri, M., Maccagnani, B., Maini, S., Bellini, R., 2015. Macrocyclops albidus (Copepoda: Cyclopidae) for the biocontrol of Aedes albopictus and Culex pipiens in Italy. J. Am. Mosq. Control Assoc. 31(1), 32-43. https://doi.org/10.2987/13-6381.1.

Vonesh, J.R., Blaustein, L., 2010. Implications of predator-induced shifts in mosquito oviposition site selection for vector control: a meta-analysis. Israel J. Ecol. Evol. 56(3-4), 263-279. https://doi.org/10.1560/ijee.56.3-4.263.

Wachira, S.W., Ndung’u, M., Njagi, P.G., Hassanali, A., 2010. Comparative responses of ovipositing Anopheles gambiae and Culex quinquefasciatus females to the presence of Culex egg rafts and larvae. Med. Vet. Entomol. 24(4), 369-374.

Wasserman, R.J., Alexander, M.E., Weyl, O.L.F., Barrios-O'Neill, D., Froneman, P.W., Dalu, T., 2016. Emergent effects of habitat complexity and temperature on predatorprey interactions. Ecosphere, 7(2), e01239. http://dx.doi.org/10.1002/ecs2.1239.

World Health Organisation, 2017. Vector-borne diseases fact sheet.

http://www.who.int/mediacentre/factsheets/fs387/en/ (accessed 01 December 2017).

Yee, D.A., 2008. Tires as habitats for mosquitoes: A review of studies within the eastern United States. J. Med. Entomol. 45(4), 581-593S. https://doi.org/10.1603/0022$\underline{2585(2008) 45[581: \operatorname{tahfma}] 2.0 . \operatorname{co} ; 2 .}$ 

Yee, D.A., 2016. Thirty years of Aedes albopictus (Diptera: Culicidae) in America: 629 An introduction to current perspectives and future challenges. J. Med. Entomol. 53(5), 989991. https://doi.org/10.1093/jme/tjw063.

631

632 Zuharah, W.F., Lester, P.J., 2010. Can adults of the New Zealand mosquito Culex 633 pervigilans (Bergorth) detect the presence of a key predator in larval habitats? J. Vector Ecol. 35, 100-105. https://doi.org/10.1111/j.1948-7134.2010.00065.x.

635

636

637

638

639

640

641

642

643

644

645

646 
648 Tables

649 Table 1

\begin{tabular}{lllllll} 
Predator & First order & $p$ & $h$ & $p$ & $a$ & \\
& term & & & & \\
& & & & & \\
\hline M. albidus & -0.03 & $<0.001$ & 0.03 & $<0.001$ & 2.11 & $<0.001$ \\
& & & & & & \\
M. fuscus & -0.05 & $<0.001$ & 0.04 & $<0.001$ & 3.85 & $<0.001$ \\
& & & & & & \\
& & & & & & \\
M. viridis & -0.02 & $<0.001$ & 0.04 & $<0.001$ & 1.36 & $<0.001$
\end{tabular}

650

651

652

653

654

655

656

657

658

659

660 
Table 2

Agent A, agent FR ( \pm SD) Parameter Reproductive RCP CIs (60\%),

B comparison $\quad$ effort $\quad p_{\text {RIP }}>1(\%)$

\begin{tabular}{|c|c|c|c|c|c|}
\hline M. albidus, $M$. & $35.72( \pm$ & $1 / h$ & 0.35 , & 2.73 & $2.03-3.36$ \\
\hline fuscus & $\begin{array}{l}7.15), 24.06 \\
( \pm 5.41)\end{array}$ & & 0.20 & & $99.94 * * *$ \\
\hline M. albidus, $M$. & $35.72( \pm$ & $1 / h$ & 0.35 , & 1.33 & $1.02-1.61$, \\
\hline viridis & $\begin{array}{l}7.15), 26.30 \\
( \pm 4.82)\end{array}$ & & 0.37 & & 82.13 \\
\hline M. viridis, $M$. & $26.30( \pm$ & $1 / h$ & 0.37 , & 2.13 & $1.60-2.60$ \\
\hline fuscus & $\begin{array}{l}4.82), 24.06 \\
( \pm 5.41)\end{array}$ & & 0.20 & & $99.35 * *$ \\
\hline M. albidus, $M$. & 2.04 & $a$ & 0.35 , & 0.96 & $0.68-1.21$ \\
\hline fuscus & $\begin{array}{l}0.36), 4.03 \\
( \pm 1.20)\end{array}$ & & 0.20 & & 39.10 \\
\hline M. albidus, $M$. & 2.04 & $a$ & 0.35, & 1.42 & $1.09-1.71$, \\
\hline viridis & $\begin{array}{l}0.36), 1.42 \\
( \pm 0.29)\end{array}$ & & 0.37 & & 87.82 \\
\hline M. viridis, $M$. & $1.42( \pm$ & $a$ & 0.37, & 0.71 & $0.49-0.90$ \\
\hline fuscus & $\begin{array}{l}0.29), 4.03 \\
( \pm 1.20)\end{array}$ & & 0.20 & & 12.63 \\
\hline
\end{tabular}

662

663 
665 Table 3

Habitat First order $p \quad h \quad p \quad p \quad p$

complexity term

\begin{tabular}{lllllll}
\hline Low & -0.03 & $<0.001$ & 0.04 & $<0.001$ & 1.68 & $<0.001$
\end{tabular}

$\begin{array}{llllll}\text { High } & -0.02 & <0.001 & 0.04 & <0.001 & 0.90\end{array}$

\section{6}

667

668

669

670

671

672

673

674

675

676

677

678 
680

681

682

683

684

685

686

687

688

689

690

691

692

693

694

695

696

697

698

699

700

701

\section{Captions}

Table 1. First order terms resulting from logistic regression (proportion of prey killed versus prey density) for each predator species in Experiment 1, alongside functional response parameter estimates ( $h$, handling time; $a$, attack rate) resulting from Rogers' random predator equation.

Table 2. Relative Control Potential (RCP; means) calculations between species using bootstrapped ( $n=30$ per parameter) maximum feeding rates $(1 / h)$ and attack rates $(a)$ with reproductive effort data (Maier, 1994). Uncertainties are reflected through CIs. Asterisks denote significant levels of certainty that the RCP score is greater than $1(*>95 \%$, ** > 99\%, $* * *>99.9 \%)$.

Table 3. First order terms resulting from logistic regression (proportion of prey killed versus prey density) for each level of habitat complexity in Experiment 2, alongside functional response parameter estimates ( $h$, handling time; $a$, attack rate) resulting from Rogers' random predator equation.

Figure 1. Illustration of low and high habitat complexity treatment arenas used in Experiment 2.

Figure 2. Functional responses of M. albidus (a), M. fuscus (b) and M. viridis (c) towards $C$. quinquefasciatus prey over a 24 hour experimental period. Means are \pm SE $(n=3$ per density)

Figure 3. Bootstrapped functional response parameters (handling time, a; maximum feeding rate, b; attack rate, c) of M. albidus, M. fuscus and M. viridis towards C. quinquefasciatus. Means are $\pm \operatorname{SE}(n=30$ per parameter $)$. 
702

703

704

705

706

707

708

709

710

711

712

713

714

715

716

717

718

719

720

721

722

723

Figure 4. RCP biplot integrating mean bootstrapped maximum feeding rate (a) and attack rate (b) and reproductive effort (Maier, 1994) for each predator. Increasing efficacy is projected from bottom left to top right. Means are \pm SE ( $n=30$ per FR parameter).

Figure 5. Functional responses of M. albidus towards C. quinquefasciatus prey under low and high habitat complexity over a 24 hour experimental period. Means are \pm SE $(n=3$ per density).

Figure 6. Bootstrapped functional response parameters (handling time, a; maximum feeding rate, b; attack rate, c) of M. albidus towards C. quinquefasciatus under low and high habitat complexity. Means are $\pm \operatorname{SE}(n=30$ per parameter $)$.

Figure 7. Oviposition activity index values (OAI, $\pm \mathrm{SE}$ ) shown by $C$. quinquefasciatus resulting from pairwise tests with predator-free controls and treatments cups inoculated with: (a) three physically-present $M$. albidus ( $n=7)$; (b) the cues emitted by three removed $M$. albidus ( $n=13)$; (c) ten ground M. albidus $(n=7)$; (d) three physically-present M. albidus in dyed water with a dyed control $(n=7)$; (e) three physically present $M$. albidus in dyed water with an undyed control $(n=7)$. Controls in bioassays (a) - (c) comprised undyed arenas. OAI values of 0 indicate no preference between predator-control treatments, with values closer to 1 indicating an increasing preference for controls (i.e. predator avoidance), and those closer to 1 indicating increasing selection for predator-treated water. Labels above indicate significance levels resulting from statistical tests using raw oviposition data $(p: *<0.05, * *<$ $0.01, * * *<0.001, \mathrm{NS} \geq 0.05)$. 


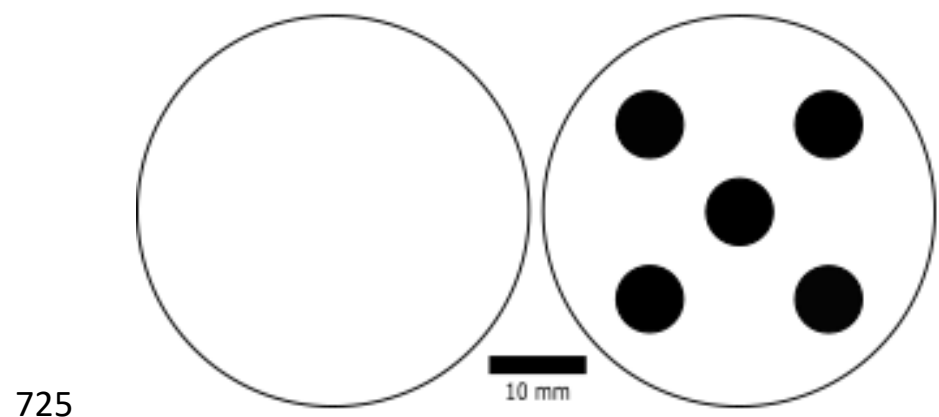

726

727

728

729

730

731

732

733

734

735

736

737

738

739

740 

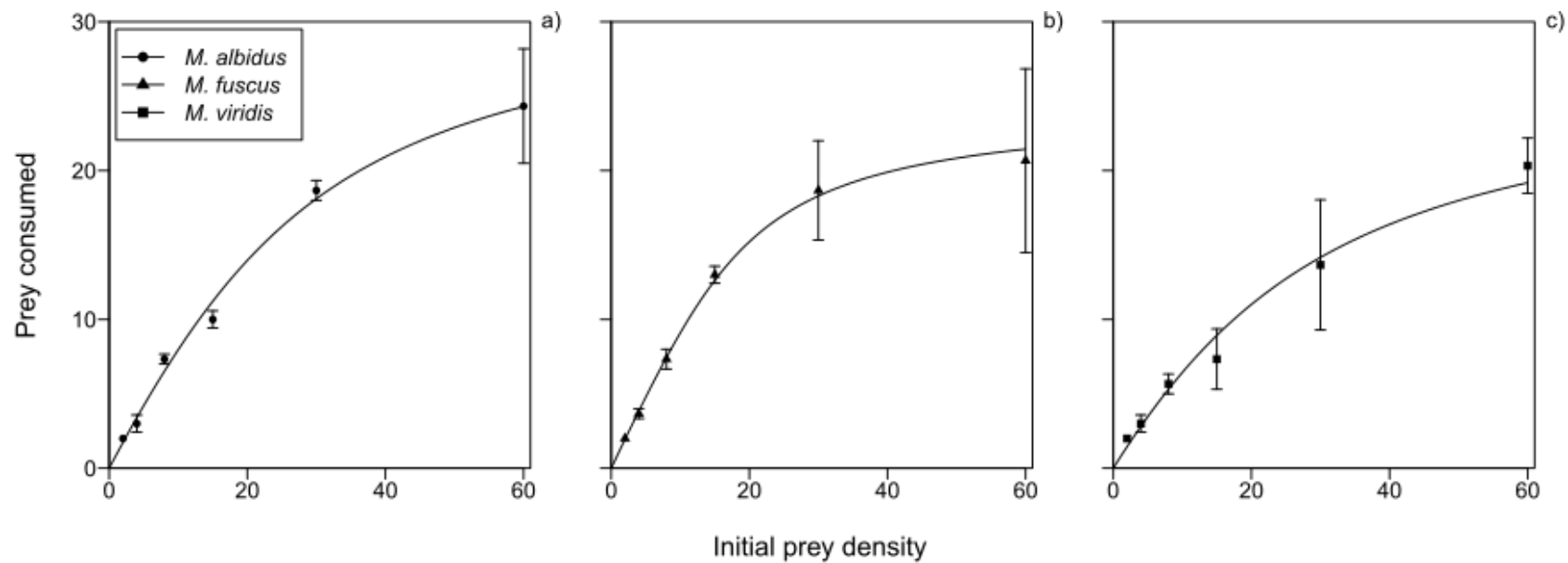

742

Initial prey density

745

746

747

748

749

750

751

752

753

754

755

756 


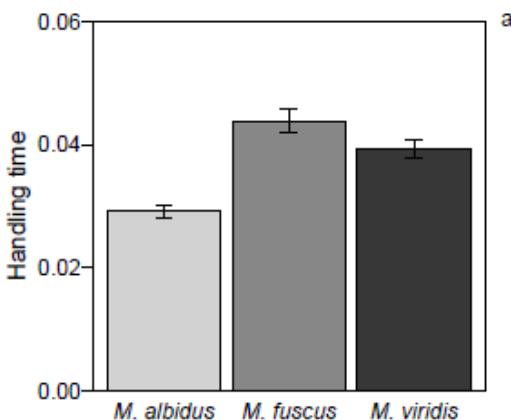

757

758

759

760

761

762

763

764

765

766

767

768

769

770

771

772

8

9

0

1

2

33

64

65

66

67

68

69

2
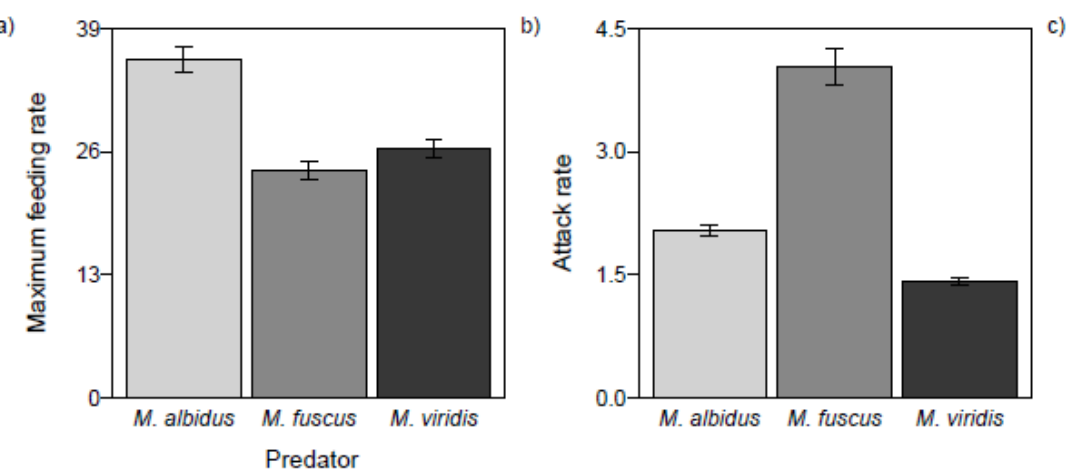


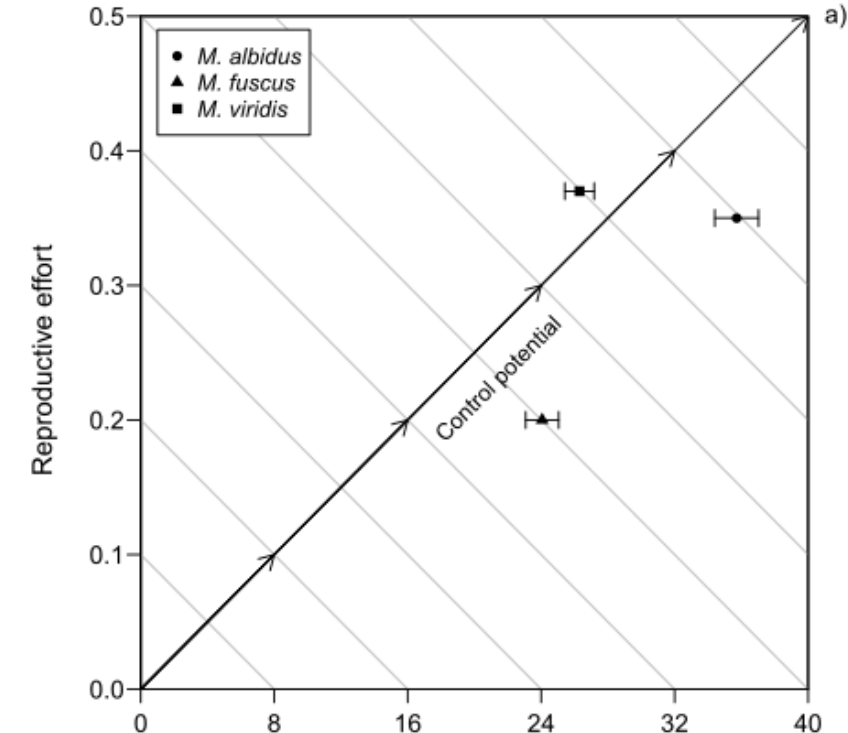

Prey/24 hours

773

FR (maximum feeding rate)

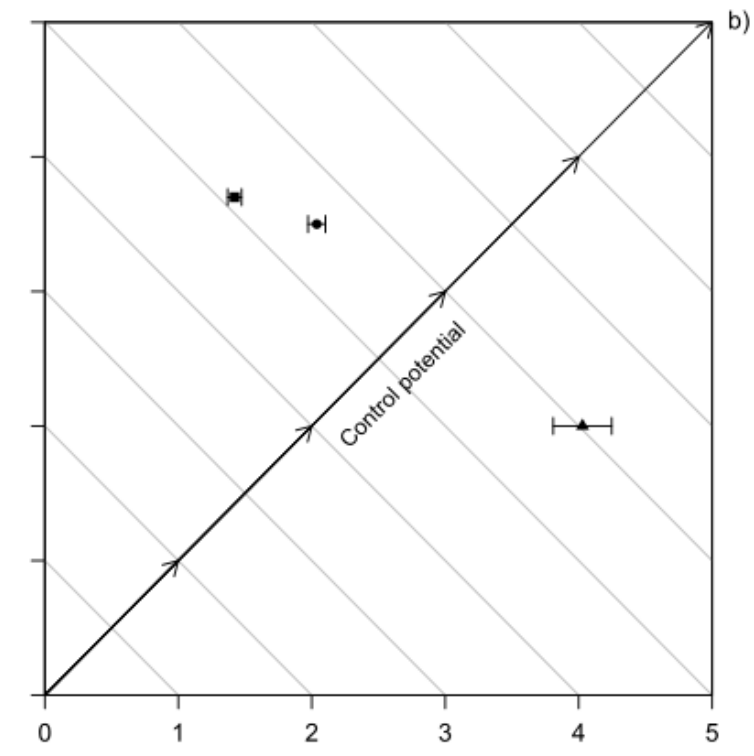

FR (attack rate)

774

775

776

777

778

779

780

781

782

783

784 


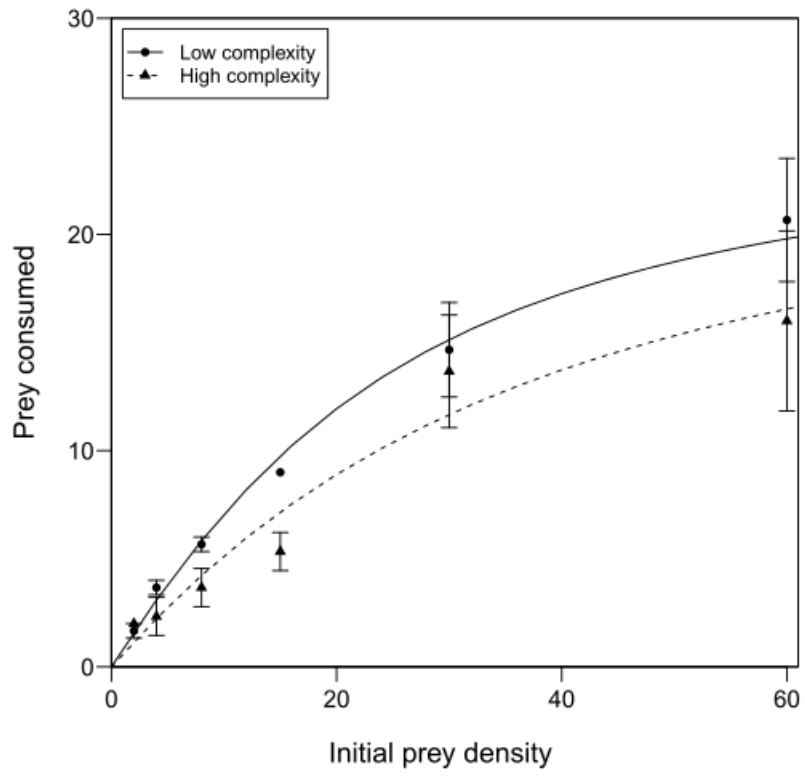

786

787

788

789

790

791

792

793

794

795

796

797

798

799 

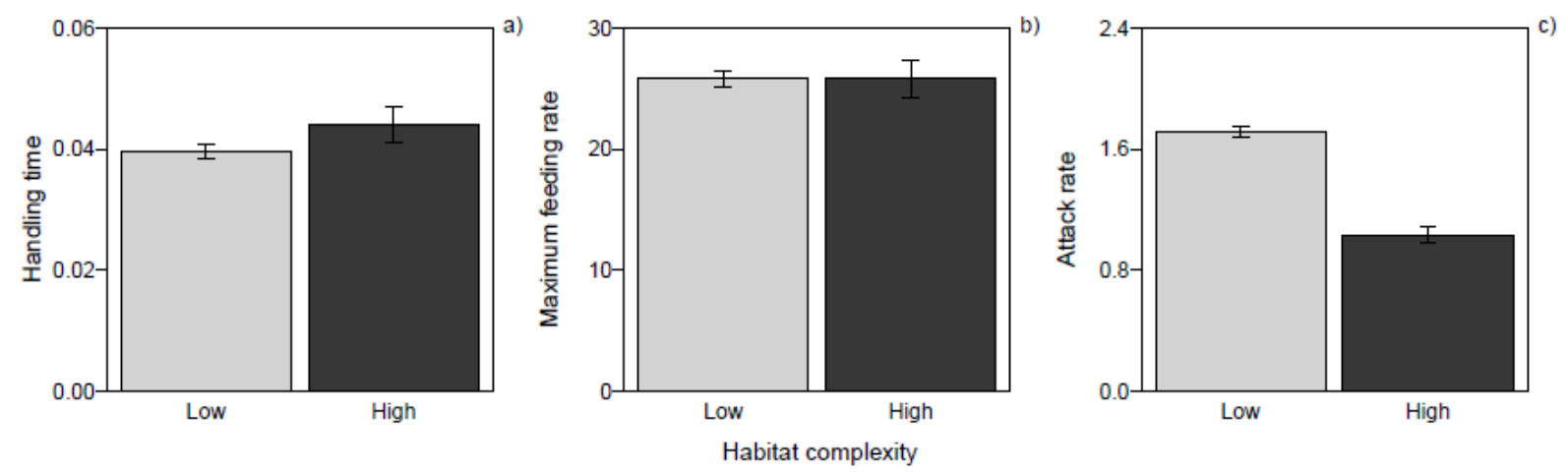

800

801

802

803

804

805

806

807

808

809

810

811

812

813

814

815 


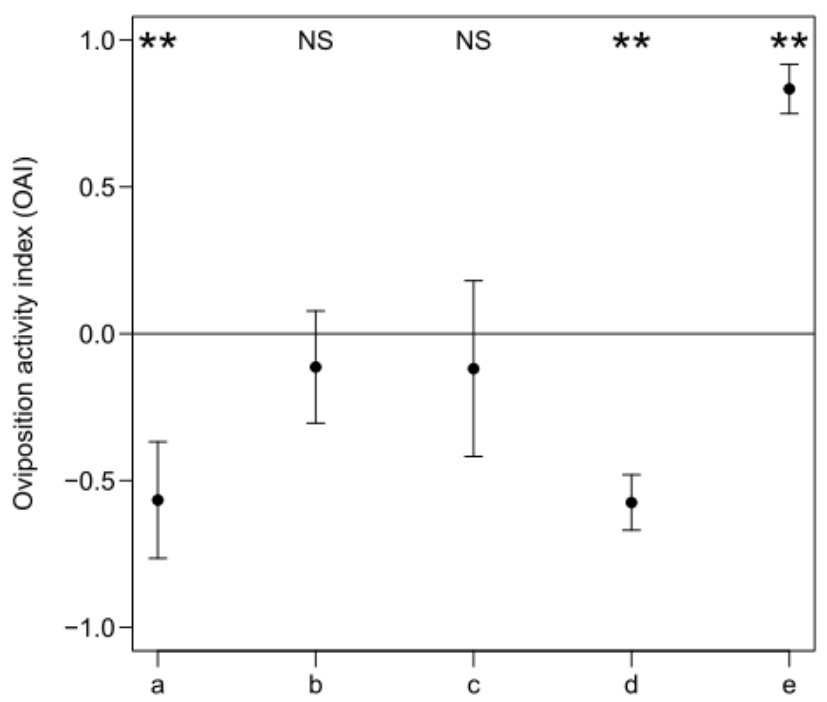

816

Predator treatment 